\title{
Magnetic Resonance Imaging Analysis of Morphological Parameters in Anterior Cruciate Ligament Injury
}

\section{ABSTRACT}

Introduction: Factors associated with Anterior Cruciate Ligament (ACL) injury are multiple. Among the anatomical factors, intercondylar notch width and alpha angle are also implicated as a cause for ACL injury. Magnetic Resonance Imaging (MRI) of the knee joint is helpful in identifying the ACL injury and factors predisposing it.

Aim: To study the alpha angle and intercondylar notch width, analysed by MRI among ACL injured cases and compare with that of controls.

Materials and Methods: In this retrospective study, MRI knee of 450 patients (18-60 years, 296 males, 154 females) were evaluated for ACL injury and were grouped under cases (torn ACL) and controls (intact $A C L$ ) with 225 participants in each group. Continuous variables were expressed as the mean \pm Standard Deviation (SD). Means of normal variables were compared using student's t-test and means of non parametric variables using Mann-Whitney $U$ test. Comparison of counts and percentages was carried out using the Chi-square $\left(\chi^{2}\right)$ test.

Results: There was no significant difference in alpha angle between males and females. Highly significant difference in intercondylar notch width was seen between males and females $(22.46 \pm 2.54 \mathrm{~mm}$ vs $21.61 \pm 2.48 \mathrm{~mm}$, p-value=0.002). Males had higher ACL injury compared to females. The mean alpha angle was higher in patients with a torn ACL than in those with an intact one (51.88 \pm 3.72 vs $50.57 \pm 3.46, p<0.001)$. In torn group intercondylar notch width was lower than intact group and this difference was significant $(21.18 \pm 2.67 \mathrm{~mm}$ vs $23.16 \pm 1.99 \mathrm{~mm}, \mathrm{p}<0.001)$.

Conclusion: Study results revealed that the ACL tears were associated with high alpha angle and narrow intercondylar notch width. ACL tears occur more frequently in men than in women and also most commonly involves age group between $31-40$ years.

Keywords: Alpha angle, Anthropometric measures, Intercondylar notch width, Knee osteoarthritis

\section{INTRODUCTION}

The ACL restraints anterior translation of tibia on the femur and provides rotational stability to the knee joint in both frontal and transverse planes. ACL injury is serious and the aetiology is multifactorial [1-3]. Few studies have shown joint anatomy and morphology are the predisposing factors for ACL injury [2,3]. In morphological factors intercondylar notch width, notch stenosis and shape of the notch are important factors [1,2]. Alpha angle is the angle between the longitudinal femoral axis and Blumensaat Line $(\mathrm{BL})$. It is increased in torn ACL knee joints compared to the normal knee joints. This angle is measured in sagittal section [1]. In this study, using MRI authors seek to further explore the role of alpha angle in ACL injury. In this study, intercondylar notch width was measured in an axial section as the lowest distance between the two condyles. Narrow intercondylar notch has smaller $\mathrm{ACL}$ and additionally there is impingement of $\mathrm{ACL}$ at the anterior and posterior roof of the notch and also stretches the ACL over the medial edge of the lateral femoral condyle hence predisposing it for tear $[1,3]$. Study by Domzalski M et al., using MRI found that a narrower intercondylar notch was associated with the risk of ACL rupture in an immature population [2]. Souryal TO et al., conducted a study to measure intercondylar notch using conventional radiograph [3]. Later similar measurements were made using Computed Tomography (CT) and MRI [2].

An identification of the predisposing factors for ACL injury in the knee may help reduce the number of ACL injuries [4-9]. Hence, this study was conducted to measure two morphological factors i.e., alpha angle and intercondylar notch width using MRI and its importance in $\mathrm{ACL}$ injured patients.

\section{MATERIALS AND METHODS}

This retrospective study was conducted in Father Muller's Medical College and Hospital for one year duration from November 2018-
November 2019 (analysis of data was done for one month duration December 2019) after obtaining the ethical clearance from our college Ethics Committee with approval number FMIEC/ CCM/56/2020.

Inclusion criteria: Patients between 18-60 years of age, who already underwent MRI knee joint, for knee joint injuries and other knee problems between the period of November 2018 to November 2019 at our hospital, were considered for this study.

Exclusion criteria: In this study, 23 patients, in whom MRI showed significant distortion of knee joint anatomy because of trauma or any previous intervention to the knee causing difficulty in measuring the objective parameters were excluded.

Sample size: A total of 450 patients, who underwent MRI knee joint, for knee joint injuries and other knee problems between the period of November 2018 to November 2019 were selected. Among them 296 were males and 154 females.

\section{Study Procedure}

Patients knee joint images were obtained from hospital Picture Archiving and Communication System (PACS) and consent waiver form was submitted. Patients with ACL injury were grouped as cases (torn group) and those without any ligament injury were grouped as controls (intact group). Controls age and sex were matched with that of the cases. MRI were obtained from 1.5 tesla Philips Acheiva MR scanner. In Proton Density Weighted- Spectral Presaturation with Inversion Recovery (PDW SPIR) Axial section, the intercondylar notch width was measured as the narrowest distance between the two femoral condyles [1]. In PDW-SPIR Sagittal section alpha angle was measured as angle formed between the BL and long axis of femur. In a sagittal section where entire intercondylar notch is seen $\mathrm{BL}$ is drawn along the roof of the 
intercondylar notch of the femur and another line is drawn along the long axis of the femur, the angle intercepted is alpha angle [Table/Fig-1] [1].

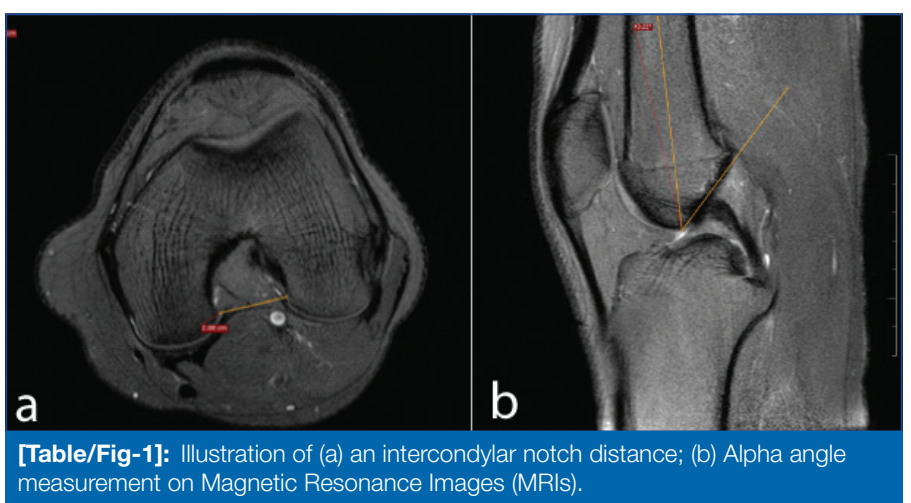

\section{STATISTICAL ANALYSIS}

Statistical analysis was done using Statistical Package for the Social Sciences (SPSS) 20.0 software. Continuous variables were expressed as the mean $\pm S D$. Normality was checked with Kolmogorov-Smirnov test. Means of normal variables were compared using student's t-test and means of non parametric variables using Mann-Whitney $U$ test. Comparison of counts and percentages was carried out using the $\chi^{2}$ test. Statistical significance of the variables in the study was confirmed with the Wald test. Odds Ratios (ORs) and their respective 95\% Confidence Interval (Cl) were also estimated. Binary logistic regression analysis was performed to determine the influence of the different variables on the ACL status. A Receiver Operating Characteristic $(\mathrm{ROC})$ curve was constructed for predicted probability of the logistic regression equation and $\mathrm{p}<0.05$ was considered statistically significant.

\section{RESULTS}

Out of 450 study population of 296-males and 154-females, 171 (76\%) of males and 54 (24\%) females had torn ACL. In this study sample, mean age for the torn group was 34.17 \pm 8.65 years [Table/Fig-2].

\begin{tabular}{|c|c|c|c|c|}
\hline \multirow[b]{2}{*}{ Variables } & Intact $(n=225)$ & Torn $(n=225)$ & & \multirow[b]{2}{*}{$\mathrm{p}$-value } \\
\hline & Mean $\pm S D$ & Mean $\pm S D$ & & \\
\hline Age (years) & $42.18 \pm 10.55$ & $34.17 \pm 8.65$ & 8.805 & $<0.001$ \\
\hline Alpha Angle (Deg) & $50.57 \pm 3.46$ & $51.88 \pm 3.72$ & -3.869 & $<0.001$ \\
\hline $\begin{array}{l}\text { Intercondylar notch } \\
\text { width (mm) }\end{array}$ & $23.16 \pm 1.99$ & $21.18 \pm$ & 8.933 & $<0$ \\
\hline
\end{tabular}

[Table/Fig-2]: Comparison of age and morphological parameters between the

patients with intact and torn anterior cruciate ligaments using student t-test and $\chi^{2}$-test.

Comparison of morphological parameters between intact and torn group: Alpha angle in torn group and in intact group was statistically significant $(p<0.001)$. Intercondylar notch width in torn when compared with intact group was also statistically significant $(p<0.001)$ [Table/Fig-2].

\section{Comparison of morphological parameters between the genders:} Males has higher intercondylar notch width compared to females and showed significant difference $(p=0.002)$. No significant difference in alpha angle was found between the genders ( $p=0.426)$ [Table/Fig-3].

Binary logistic regression analysis model was done in the present study to show the effect of all the variables included in this study on ACL status as a dependent variable. Age with OR of 0.917 has negligible effect on ACL status. Odds of having an ACL injury are 3.4 times higher among males [Table/Fig-4]. Alpha angle with OR 1.172 has negligible positive influence on ACL status. OR for Intercondylar notch width is 0.671 , that means intercondylar notch and ACL tear are inversely related. Narrow intercondylar notch has a negative influence on ACL status [Table/Fig-4].

\begin{tabular}{|c|c|c|c|c|c|c|c|}
\hline Variables & & & Mean \pm SD & $\begin{array}{l}\text { Median } \\
\text { (IQR) }\end{array}$ & Range & $\begin{array}{c}\text { Mann- } \\
\text { whitney U }\end{array}$ & $\begin{array}{c}\mathrm{p}- \\
\text { value }\end{array}$ \\
\hline \multirow{2}{*}{ Alpha angle } & Male & 296 & $51.31 \pm 3.77$ & $\begin{array}{c}52.06 \\
(48.83,54.23)\end{array}$ & $\begin{array}{c}39.57- \\
59.98\end{array}$ & \multirow{2}{*}{21749.500} & \multirow{2}{*}{0.426} \\
\hline & Female & 154 & $51.06 \pm 3.4$ & $\begin{array}{c}51.36 \\
(49.67,53.35)\end{array}$ & $\begin{array}{l}40.23- \\
58.37\end{array}$ & & \\
\hline \multirow{2}{*}{$\begin{array}{l}\text { Intercondylar } \\
\text { notch width } \\
(\mathrm{mm})\end{array}$} & Male & 296 & $22.46 \pm 2.54$ & $\begin{array}{c}22.6 \\
(20.5,24.35)\end{array}$ & $\begin{array}{l}16.5- \\
28.8\end{array}$ & \multirow{2}{*}{18676.500} & \multirow{2}{*}{0.002} \\
\hline & Female & 154 & $21.61 \pm 2.48$ & $\begin{array}{c}21.7 \\
(20.1,23.7)\end{array}$ & $\begin{array}{l}15.6- \\
26.5\end{array}$ & & \\
\hline
\end{tabular}

[Table/Fig-3]: Comparison of morphological parameters between the genders using Mann-Whitney $U$ test and $p$-value using $\chi^{2}$ test.

\begin{tabular}{|l|c|c|c|c|c|c|c|c|}
\hline \multicolumn{10}{|c|}{ Step 1 } & & & & & & & \multicolumn{2}{|c|}{$\begin{array}{c}95 \% \text { CI for } \\
\text { odds ratio }\end{array}$} \\
\hline Age & B & S.E. & Wald & df & Sig. & $\begin{array}{c}\text { Odds } \\
\text { ratio }\end{array}$ & Lower & Upper \\
\hline $\begin{array}{l}\text { Gender } \\
\text { (male) }\end{array}$ & -0.087 & 0.013 & 47.245 & 1 & $<0.001$ & 0.917 & 0.894 & 0.940 \\
\hline Alpha angle & 0.159 & 0.033 & 22.680 & 1 & $<0.001$ & 1.172 & 1.098 & 1.251 \\
\hline $\begin{array}{l}\text { Intercondylar } \\
\text { notch width }\end{array}$ & -0.399 & 0.054 & 54.680 & 1 & $<0.001$ & 0.671 & 0.604 & 0.746 \\
\hline Constant & 3.222 & 1.941 & 2.755 & 1 & 0.097 & 25.068 & & \\
\hline
\end{tabular}

[Table/Fig-4]: A binary logistic regression analysis model was done to study the effect of all the variables included in present study on $\mathrm{ACL}$ status as a dependent variable. a. Variable(s) entered on step 1: Age, Gender, Alpha angle, Width

The ROC curve for predicted probability of the logistic regression equation analysis was constructed using the variables studied in binary logistic regression analysis. Area under the curve is 0.840 (95\% Cl, 0.804-0.877; $p<0.001)$ indicates that factors studied in this model are the excellent predictor for ACL injury [Table/Fig-5].

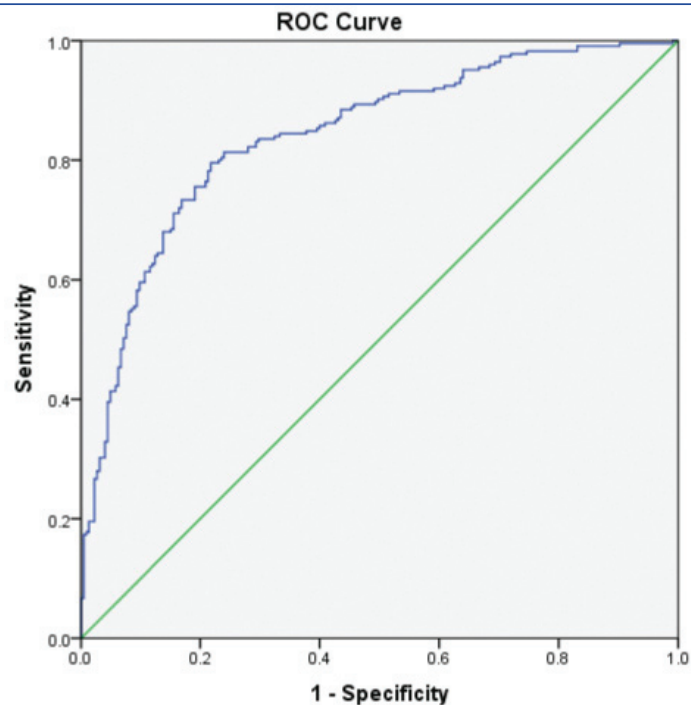

[Table/Fig-5]: ROC curve for predicted probability of the logistic regression equation analysis Area under the curve more than 0.840 (95\% Cl, 0.804-0.877; $p<0.001)$.

Study population correctly and incorrectly classified by this study, taking a predicted probability value of 0.50 as a cut-off. Sensitivity of this study is $77.8 \%$ and specificity is $78.7 \%$. Positive predictive value is $77.78 \%$ and negative predictive value is $78.67 \%$. Overall accuracy of this study is $78.2 \%$ [Table/Fig-6].

\begin{tabular}{|l|l|c|c|c|}
\hline \multirow{2}{*}{\multicolumn{2}{|c|}{}} & \multicolumn{3}{c|}{ Predicted by study } \\
\cline { 3 - 5 } \multicolumn{2}{|l|}{ Observed (N=450) } & \multicolumn{2}{|c|}{ Group (intact/torn) } & \multirow{2}{*}{$\begin{array}{c}\text { \% of Patients correctly } \\
\text { classified }\end{array}$} \\
\cline { 2 - 4 } & Intact & Torn & 78.7 \\
\hline \multirow{2}{*}{ Group (intact/torn) } & Intact & 177 & 48 & 77.8 \\
\cline { 2 - 5 } & Torn & 50 & 175 & 78.2 \\
\hline \multicolumn{2}{|l|}{ Overall Percentage } & & & 78.7 \\
\hline
\end{tabular}

[Table/Fig-6]: Number of patients correctly and incorrectly classified by the binary logistic regression model (cut-off value is 0.50 ). 


\section{DISCUSSION}

In this study, torn group had higher alpha angle compared to the intact one. Mean value for torn group is $51.88 \pm 3.72 \mathrm{~mm}$. This finding was in agreement with the finding from the study by Fernández-Jaén T et al., where mean value of torn group was $57.5 \pm 5.5 \mathrm{~mm}$ [1].

In this study, intercondylar notch width in torn group was narrow compared to intact group. Mean value for torn group was $21.18 \pm 2.67 \mathrm{~mm}$. This finding was in agreement with the study by Fernández-Jaén T et al., (mean value was 18.2+3.1mm) [1]. There was an inverse relationship between an intercondylar notch width and ACL injury. This relationship was proven by many other studies in the past like Domzalski $M$ et al., Souryal TO et al., etc., [2,3]. Study by Domzalski $\mathrm{M}$ et al., found that a narrower intercondylar notch was found to be associated with the risk of ACL rupture in an immature population (11-17 years). They measured notch width index using MRI. The mean values were 0.2438 for torn group and 0.2641 in the control population [2]. Souryal TO et al., conducted a prospective study using conventional X-ray on high school athletes and found that athletes with a stenotic intercondylar notch (notch width index, 0.189) are at significantly greater risk for sustaining non contact ACL injury [3].

In present study, males had higher intercondylar notch width compared to females which was consistent with findings by Fernández-Jaén $T$ et al., Souryal TO et al., and Hirtler $L$ et al., $[1,3,5]$. Souryal TO et al., reasoned that intercondylar notch in males occupies more space in the distal femur than it does in females and also because of large body stature [3]. In present study, it was found that males had higher risk of having ACL tear compared to females. This finding was in agreement with the studies by Fernández-Jaén $T$ et al., Domzalski $M$ et al., and Souryal TO et al., [1-3]. There was no significant difference in alpha angle between the genders consistent with study by Fernández-Jaén $T$ et al., and Huang $M$ et al., $[1,10]$. Binary logistic regression analysis showed there was negligible effect of alpha angle and age on ACL injury status was consistent with finding by Fernández-Jaén T et al., [1]. Also, there are many such studies done on young athletic population since they are at high risk of ACL tear because these activities place a high stress on ACL which is already being compromised here by the narrow intercondylar notch [4-11].

This study was done to evaluate two morphological factors predisposing to ACL injury. Hence, identifying that risk factors plays a crucial role in the management of patients with anterior knee pain, early Osteoarthritis $(O A)$ changes or $A C L$ tear. Since narrow intercondylar notch can be the cause behind these conditions [12-14].

\section{Limitation(s)}

In this study, authors had measured intercondylar notch width in a 2D MRI image. The measurement of notch width may differ owing to the alignment of knee during imaging. In present study, authors had considered age group between 18-60 years. Authors have studied the two morphological factors in them without considering the age related changes in size and shape of the femoral condyles affecting the measured morphological parameters.

\section{CONCLUSION(S)}

In this study, authors have measured two morphological parameters in an ACL injured patient's i.e., alpha angle and intercondylar notch width. Both these parameters have an effect on ACL status. High alpha angle causes impingement of $\mathrm{ACL}$ against the anterior intercondylar notch on extension. Narrow intercondylar notch houses small ACL and stretches the ACL over medial edge of lateral femoral condyle predisposing it for tear. Younger age groups are more likely affected by this condition due to increased participation in sports. $\mathrm{MRI}$ is the most common modality used to diagnose ACL injury. Understanding the predisposing factors for ACL tear is important so that such findings are picked up and promptly reported so that it makes a difference in patient's management.

\section{REFERENCES}

[1] Fernández-Jaén $T$, Juan $M L$, Elena R, Pedro G. The importance of the intercondylar notch in anterior cruciate ligament tears. The Orthopaedic Journal of Sports Medicine. 2015;3(8):117.

[2] Domzalski M, Grzelak P, Gabos P. Risk factors for anterior cruciate ligament injury in skeletally immature patients: Analysis of intercondylar notch width using magnetic resonance imaging. Int Orthop. 2010;34:703-07.

[3] Souryal TO, Moore HA, Evans JP. Bilaterality in anterior cruciate ligament injuries. Am J Sports Med. 1988;16:449-54.

[4] Geng B, Wang J, Ma JL, Zhang B, Jiang J, Tan XY, et al. Narrow intercondylar notch and anterior cruciate ligament injury in female nonathletes with knee osteoarthritis aged 41-65 years in plateau region. Chin Med J. 2016;129:254-55.

[5] Hirtler L, Röhrich S, Kainberger F. The femoral intercondylar notch during life: An anatomic redefinition with patterns predisposing to cruciate ligament impingement. AJR. 2016;207:836-45.

[6] Everhart JS, Flanigan DC, Chaudhari AM. Anteromedial ridging of the femoral intercondylar notch: An anatomic study of 170 archival skeletal specimens. Knee Surg Sports Traumatol Arthrosc. 2014;22:80-88.

[7] Wang MH, Sandra JS, Randy JS. Association of anterior cruciate ligament width with anterior knee laxity. Journal of Athletic Training. 2016;51(6):460-65.

[8] Simon RA, Everhart J, Nagaraja HN, Chaudhari AM. A case-control study of anterior cruciate ligament volume, tibial plateau slopes and intercondylar notch dimensions in ACL injured knees. J Biomech. 2010;43(9):1702-07.

[9] Chaudhari AMW, Zelman EA, Flanigan DC, Kaeding CC, Nagaraja HN. Anterior cruciate ligament-injured subjects have smaller anterior cruciate ligaments than matched controls: A magnetic resonance imaging study. Am J Sports Med. 2009;37:1282-87.

[10] Huang M, Yubiao Li, Guo N, Liao C, Yu B. Relationship between intercondylar notch angle and anterior cruciate ligament injury: A magnetic resonance imaging analysis. J Int Med Res. 2019;47(4):1602-09.

[11] LaPrade RF, Burnett QM 2nd. Femoral intercondylar notch stenosis and correlation to anterior cruciate ligament injuries. A prospective study. Am J Sports Med. 1994;22:198-202.

[12] Rahnemai-Azar AA, Abebe ES, Johnson P. Increased lateral tibial slope predicts high-grade rotatory knee laxity preoperatively in ACL reconstruction. Knee Surg Sports Traumatol Arthrosc. 2017;25:1170-76.

[13] Zheng Li, Changshu Li, Li L, Wang P. Correlation between notch width index assessed via magnetic resonance imaging and risk of anterior cruciate ligament injury: an updated meta-analysis. SRA. 2020;42(10):1209-17.

[14] Bouras T, Fennema P, Burke S, Bosman H. Stenotic intercondylar notch type is correlated with anterior cruciate ligament injury in female patients using magnetic resonance imaging. Knee Surg Sports Traumatol Arthrosc. 2018;26(4):1252-57.

\section{PARTICULARS OF CONTRIBUTORS:}

1. Postgraduate Student, Department of Radiodiagnosis, Father Muller Medical College, Mangalore, Karnataka, India.

2. Senior Resident, Department of Radiodiagnosis, Father Muller Medical College, Mangalore, Karnataka, India.

3. Senior Resident, Department of Radiodiagnosis, Father Muller Medical College, Mangalore, Karnataka, India.

4. Professor, Department of Radiodiagnosis, Father Muller Medical College, Mangalore, Karnataka, India.

NAME, ADDRESS, E-MAIL ID OF THE CORRESPONDING AUTHOR:

Dr. Jennifer Dsouza,

Avemaria 'C' Block, F.M.M.C, Ladies Hostel, Kankanady, Mangalore, Karnataka, India.

E-mail: dsouzajenny1990@gmail.com

\section{AUTHOR DECLARATION:}

- Financial or Other Competing Interests: None

- Was Ethics Committee Approval obtained for this study? Yes

- Was informed consent obtained from the subjects involved in the study? No

- For any images presented appropriate consent has been obtained from the subjects. No

\section{PLAGIARISM CHECKING METHODS: [Jain Het al]}

- Plagiarism X-checker: Sep 19, 2020

- Manual Googling: May 15, 2021

- iThenticate Software: Jul 06, 2021 (10\%)
ETYMOLOGY: Author Origin

Date of Submission: Sep 18, 2020 Date of Peer Review: Jan 04, 2021 Date of Acceptance: Jun 08, 2021 Date of Publishing: Oct 01, 2021 